\title{
A consideration of two models of health and safety training for undergraduate chemists
}

\author{
James W. Gaynor \\ Department of Chemistry, University of Liverpool, Crown Street, UK, L69 7ZD
}

Corresponding author: J.W.Gaynor@liverpool.ac.uk

Keywords: Health and safety; Safety awareness; Laboratory safety; Undergraduate students; Chemistry

\begin{abstract}
An initial pilot evaluation is presented of students' awareness of health and safety training provision, and a comparison of two models of health and safety training after a curriculum redesign. The old model focussed on students generating their own $\mathrm{COSHH}$ with highly variable approaches to checking understanding across our curriculum. The new model shifted the focus more on student understanding with a more harmonious approach using research-standard safety documentation and assessment processes. The new system has elements of researchconnected teaching and authenticity with students finding the research-standard materials accessible. In terms of preparedness, each model has its benefits and some suggestions for future practice are presented.
\end{abstract}

\section{Introduction}

In the UK, all employers are governed by legislation (The National Archives, 1974) which is overseen by the Health and Safety Executive (HSE). All employers, including Higher Education Institutions (HEls) and their internal departments, must interpret the rather flexible HSE policies appropriately. Considering the potential for variety, one would expect plenty of educational literature about how risk awareness training is actioned for Chemistry programmes. However, whilst most lab-related educational research has a consideration of health and safety (H\&S) (Agustian \& Seery,
2017; Cranwell, et al., 2017; Blackburn, et al., 2019; Veiga, et al., 2019), rarely is an appreciation of hazard awareness the focus of the research or course redevelopment (Karapantsios, et al., 2008; Artdej, 2012; Han \& Park, 2018). This is surprising considering the Royal Society of Chemistry (RSC) has safety awareness as part of their accreditation processes (Royal Society of Chemistry, 2012) and there are numerous references to competent and employable chemists in the QAA Chemistry benchmark statements (QAA, 2014).

Chemistry educational literature which focuses on developing employable graduates tends to look at generic skills either outlined by the Confederation of British Industry (2016) or those suggested by the RSC (Hanson \& Overton, 2010; Lucas \& Rowley, 2011; Kirton, et al., 2014). Perhaps views on H\&S are longstanding within departments and overcoming these requires significant cultural change which can be a challenging process in large and complex institutions (Hill, 2016; Staehle, et al., 2016). However, there appears to be some recent movements in the field, with decent resources available in a self-learn arrangement (Royal Society of Chemistry, 2016), considerations of industrial collaborations (Huston, et al., 2018), the use of group based techniques (Alaimo, et al., 2010) and the use of more visual modes of learning through Manga (Kumasaki, et al., 2018) and interactive $360^{\circ}$ lab inductions 
A consideration of two models of health and safety training for undergraduate chemists

\begin{tabular}{|c|c|c|}
\hline & Model 1: Pre-change & Model 2: Post-change \\
\hline $\begin{array}{l}\text { Safety documentation: } \\
\text { cosHH }\end{array}$ & $\begin{array}{l}\text { Student generated in lab } \\
\text { books from internal website. } \\
\text { Marked by a demonstrator } \\
\text { before entering the lab. }\end{array}$ & $\begin{array}{l}\text { Years 1-3: Research-standard } \\
\text { COSHH provided to students using } \\
\text { departmental online COSHH system. } \\
\text { Once assessment (below) is } \\
\text { completed, students are given a } \\
\text { COSHH summary form to sign and } \\
\text { stick into their lab book. }\end{array}$ \\
\hline $\begin{array}{l}\text { Safety documentation: } \\
\text { general risk } \\
\text { assessment; working } \\
\text { with carcinogens; } \\
\text { Standard Operating } \\
\text { Procedures. }\end{array}$ & $\begin{array}{l}\text { Prepared for students by lab } \\
\text { space/module and made } \\
\text { available. }\end{array}$ & $\begin{array}{l}\text { Prepared for students by } \\
\text { experiment using our research } \\
\text { processes. }\end{array}$ \\
\hline $\begin{array}{l}\text { Assessment } \\
\text { processes: Stage } 1\end{array}$ & $\begin{array}{l}\text { Highly variable in terms of } \\
\text { implementation, content and } \\
\text { attainment reauirements }\end{array}$ & $\begin{array}{l}\text { All lab-based experiments have an } \\
\text { online safety test ( } 100 \% \text { pass mark). }\end{array}$ \\
\hline $\begin{array}{l}\text { Assessment } \\
\text { processes: Stage } 2\end{array}$ & & $\begin{array}{l}\text { Years 1/2: A second summative pre- } \\
\text { lab online test ( } 50 \% \text { pass mark), } \\
\text { and/or face-to-face discussions. }\end{array}$ \\
\hline Safety lectures & \multicolumn{2}{|c|}{$\begin{array}{l}\text { Including: New starter induction; annual NMR lectures; year } 2 \\
\text { explosion lecture; year } 3 \text { research lecture; separate module induction } \\
\text { lectures (not an exhaustive list). }\end{array}$} \\
\hline $\begin{array}{l}\text { Additional } \\
\text { assignments }\end{array}$ & $\begin{array}{l}\text { One safety assignment in } \\
\text { year } 1 \text { (MCQ, via virtual } \\
\text { learning environment). }\end{array}$ & $\begin{array}{l}\text { Including: COSHH writing; SDS; lab } \\
\text { induction online tests; group-work } \\
\text { reporting of 'near-misses'; critiquing } \\
\text { 'bad labs' scenarios using } 360^{\circ} \\
\text { images; interactive workshop linked } \\
\text { to legislation, exposure limits. }\end{array}$ \\
\hline
\end{tabular}

Table 1 Key differences in implementation of model 1 and model 2.

(Clemons, et al., 2019). The leading area of change seems to be the US, which may have been triggered by some high profiles cases globally (Benderly, 2014; Stuart \& McEwen, 2016); the American Chemical Society have encouraged a rethink to student training (Kemsley, 2009; Kemsley, 2016). This culminated in in the publication of their own benchmark statements (ACS, 2015) which explicitly states 'Laboratory Safety Skills' as one of their six key skills.

\section{Curriculum re-design Reasons for change}

The curriculum re-design took place from 2016-17 after our programmes were audited and we were prompted to make a very minor change to improve compliance. However, we decided to make more radical whole-scale changes to improve the provision for our students by harmonising the approach taken by all our pre-research laboratory courses that span years 1, 2 and half of year 3 , changing long-standing cultures within our department and updating over 70 of our undergraduate experiments. These focussed on three main areas of H\&S training: safety documentation; assessment; and new safety assignments. These are summarised in Table 1 by model 1 and model 2.

\section{Rationale for change}

The student generated $\mathrm{COSHH}$ system (model 1) was inconsistent in quality, liable to collusion issues, and not fitting with the requirements for long term record keeping, particularly when working with carcinogens which require 40 year records. The removal of 
A consideration of two models of health and safety training for undergraduate chemists

\begin{tabular}{|c|c|c|c|c|}
\hline \multicolumn{2}{|c|}{$\begin{array}{c}\text { 1) (all students) } \\
\text { What Chemistry lab modules did } \\
\text { you complete this academic } \\
\text { year? }\end{array}$} & $\begin{array}{l}\text { 2) (all students) } \\
\text { What lab modulesiexperience } \\
\text { did you complete during the last } \\
\text { academic year? }\end{array}$ & \multicolumn{2}{|c|}{$\begin{array}{l}\text { 3/4) (all students) } \\
\text { Do you feel as though your } \\
\text { health and safety training at } \\
\text { Liverpool so far has prepared } \\
\text { you sufficiently for the lab based } \\
\text { work you were doing this year? } \\
\text { Please elaborate }\end{array}$} \\
\hline & \multicolumn{3}{|c|}{$\begin{array}{l}5 / 6)(Y 1 / Y 2 / Y 3 \text { students in teaching labs) } \\
\text { ment of obtaining } 100 \% \text { pass mark on the H\&S pre-lab is a fair } \\
\text { t. } \\
\text { it took me too long to complete the pre-lab online tests to the } \\
\text { indard. } \\
\text { ed for the laboratory as a result of the pre-lab requirements. } \\
\text { the safety forms supplied to me (COSHH / General risk } \\
\text { / working with carcinogens) were easy to understand and } \\
\text { onal comments }\end{array}$} & \\
\hline $\begin{array}{l}\text { 10) (Y1 only) } \\
\text { Do you have any } \\
\text { additional thoughts } \\
\text { on the additional } \\
\text { safety assignments } \\
\text { linked to each } \\
\text { module? (Specifics } \\
\text { then given) }\end{array}$ & $\begin{array}{l}\text { a) I noticed a } \\
\text { b) The chang } \\
\text { overall. } \\
\text { c) The new s) } \\
201516 \text {. } \\
\text { d) I felt more } \\
\text { forms ( } 201 \\
\text { ( } 201617) \text {. } \\
\text { Offer any addit }\end{array}$ & $\begin{array}{l}\text { 7/8) (Y2/3 } 201617 \text { only). } \\
\text { aring H\&S processes pre-post impleme } \\
\text { rence in pre-lab activities this year com } \\
\text { lab system during } 201617 \text { was a favour } \\
201617 \text { was quicker to complete than } t \\
\text { dentering the laboratory by having to cr } \\
\text { being given the COSHH and risk asses } \\
\text { mments }\end{array}$ & $\begin{array}{l}\text { st year } \\
\text { e for me } \\
\text { em in } \\
5 \text { this year }\end{array}$ & $\begin{array}{l}\text { 9) (Y4/Y3 placement } \\
\text { students). Is there any } \\
\text { aspect of H\&S that } \\
\text { you've learnt } \\
\text { exclusively from your } \\
\text { experiences this year } \\
\text { that would have been } \\
\text { beneficial to know } \\
\text { about beforehand?? }\end{array}$ \\
\hline
\end{tabular}

Figure 1 Questions and flow of the survey. $Y 1 / Y 2$, etc., represents the year of current study. Questions 3/4/5c/7d were linked to preparedness for labs. Questions $5 a / b / d$ were linked to accessibility of the new system. Questions 7/8/9/10 were linked to awareness and attitude. Question 7 had additional text highlighting the differences between model 1 and model 2.

student-created documentation (model 2) was rationalised by enhanced assessment and new safety assignments plus ensuring students were receiving accurate and consistent information that was approved by each module coordinator. With an aim to connect our undergraduate and research processes, $\mathrm{COSHH}$ forms were created from our departmental online $\mathrm{COSHH}$ system to better prepare students when they moved into research labs. All lab-based experiments now have an online safety test that specifically focusses on chemical and general lab safety with students required to score $100 \%$ before being allowed into the lab or onto phase two of the pre-lab requirements (Table 1). For year 1 courses alone, nearly 200 new H\&S questions were created, with students being asked questions from pools which varied with each test attempt.

Whilst safety documentation and assessment was changed for all years at once, additional safety assignments were introduced in a staggered manner by being embedded into over half of lab courses spanning years 1 and 2. They aimed to have a level of authenticity and interactivity (Table 1) but will not be discussed in any more detail as part of this pilot.

\section{Pilot research questions}

The focus of this pilot was on student perceptions of H\&S training in general, with a specific look at the implications of switching from model 1 to model 2. The key questions are: Are students aware of the H\&S training provided? Has the change in focus to model 2 been accessible and helped students feel more prepared for the laboratory? Are there any perceived benefits or limitations of model 1 vs model 2?

\section{Method}

\section{Participants}

Pedagogical evaluation conformed to the University of Liverpool's ethical processes (Faculty of Science and Engineering ethics 
Question 3: General preparedness

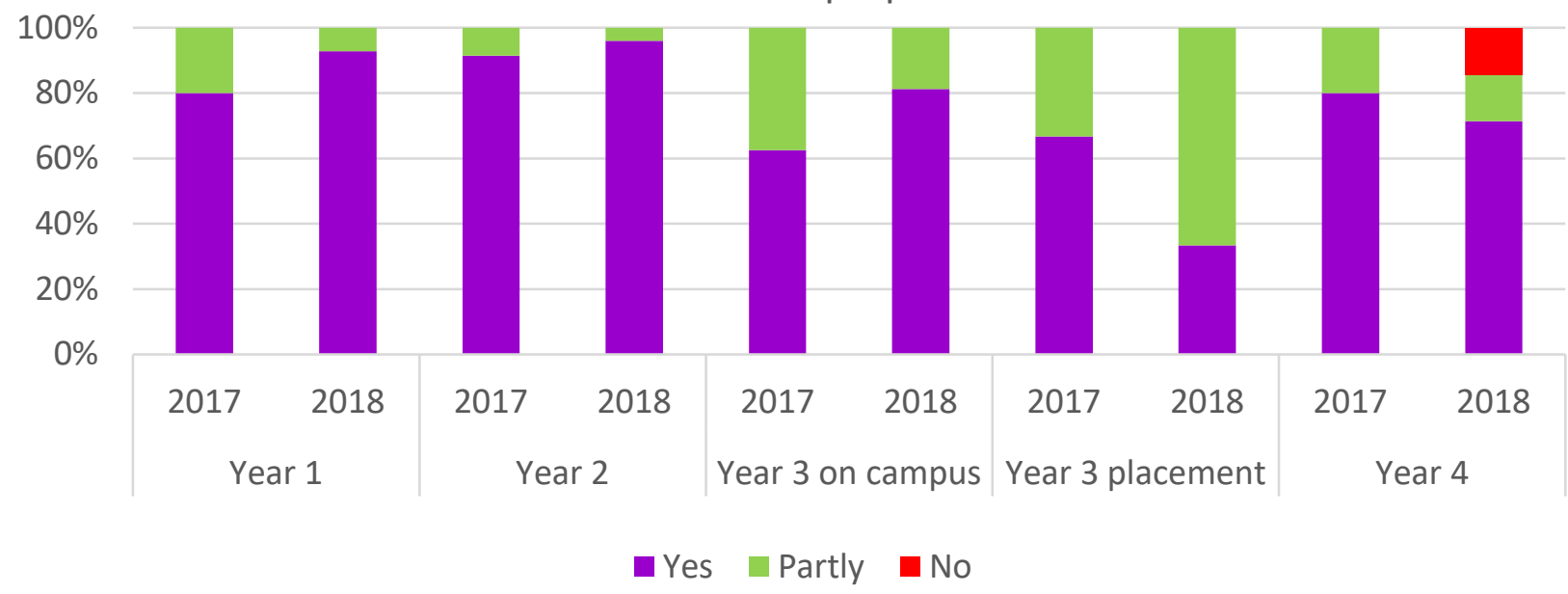

Figure 2 Response to whether H\&S training had prepared students for their current lab.

Question 5: Accessibility/Preparedness of model 2

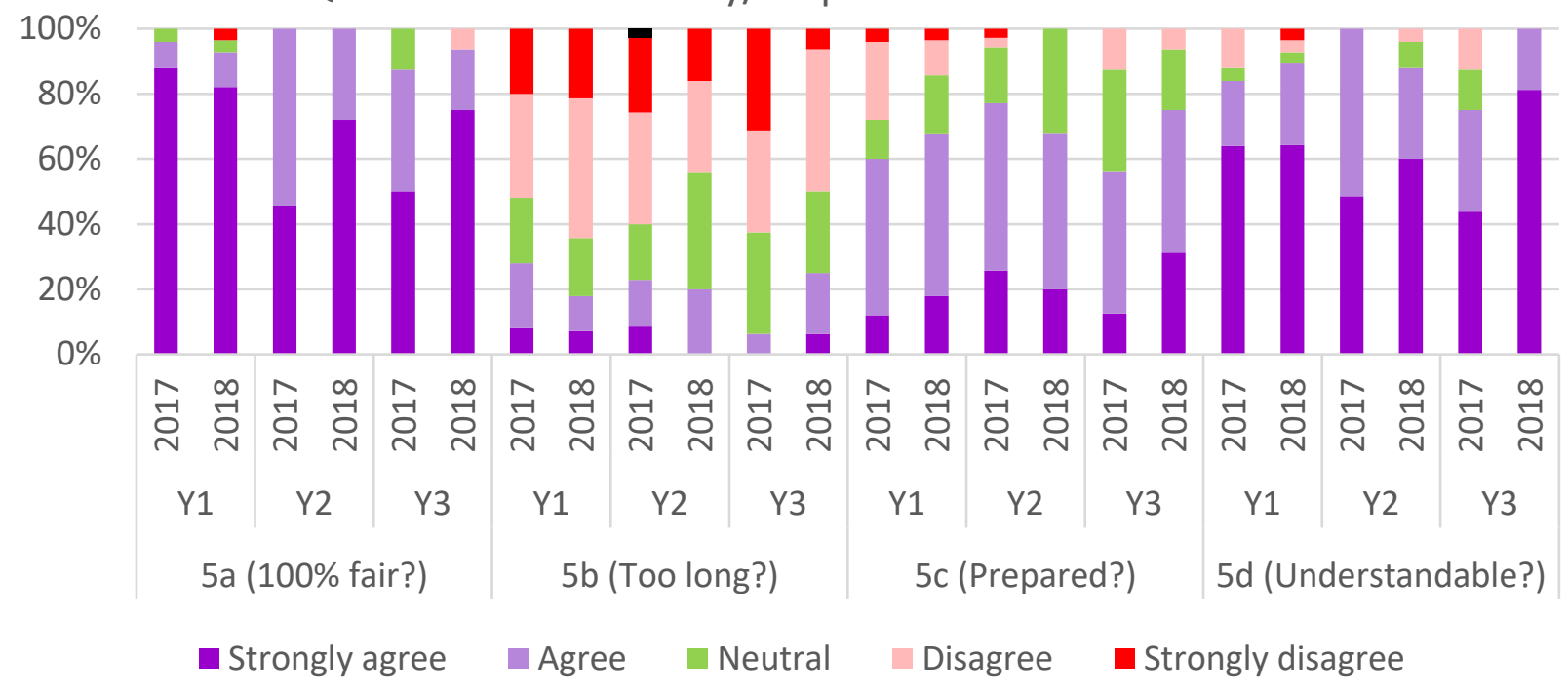

Figure 3 Response to thoughts on model 2 in terms of accessibility and preparedness.

Question 7: Response to change to model 2

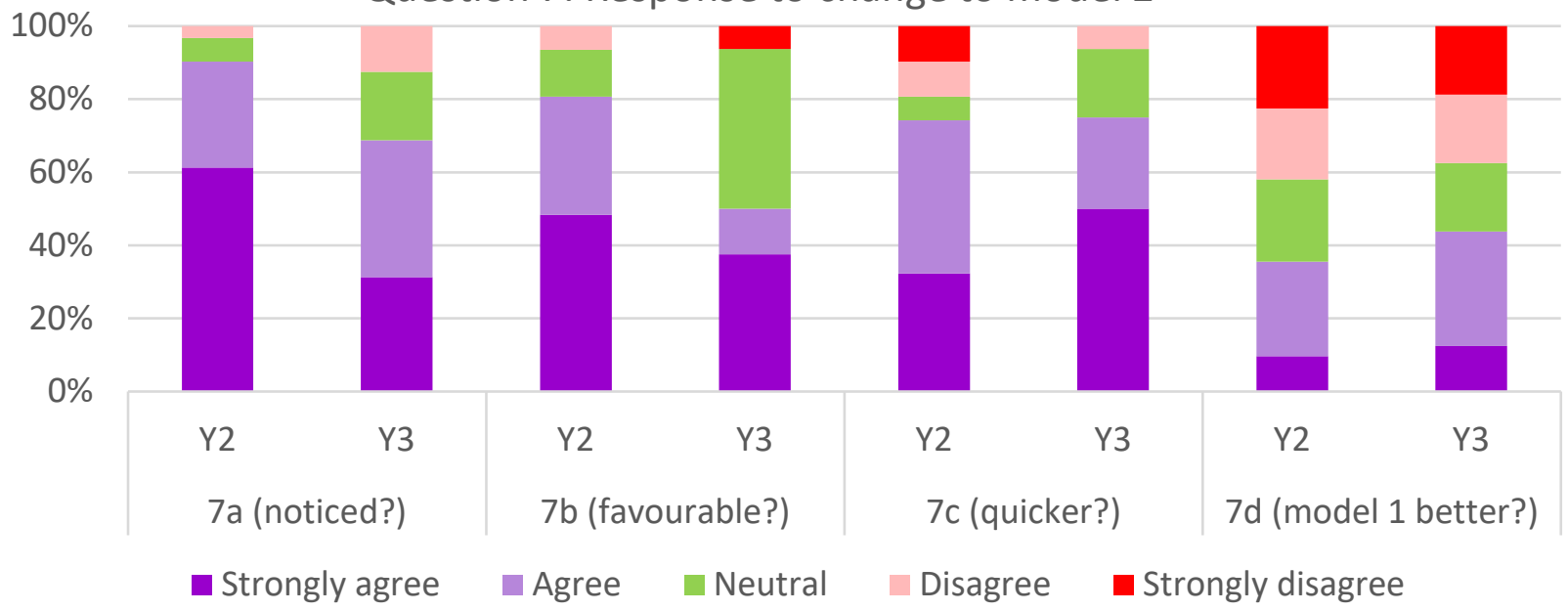

Figure 4 Response to change for students in pre-research laboratories (2017 only). 
A consideration of two models of health and safety training for undergraduate chemists

reference number 1876). Participants were sought from all years of study.

\section{Survey}

A short dynamic survey was developed (Figure 1) offering questions relevant to students at certain stages of their programme. The survey was released online (via SelectSurvey) to all undergraduates both at the end of the 2016-17 and 2017-18 academic years and closed about a month later. A few reminders were sent to students. Questions were deliberately asked sequentially to minimise influence of later questions.

\section{Student interview}

This pilot focussed on interviewing students in year 2 of study during 2016-17 as they had experienced the course re-design between years 1 and 2. The semi-structured interview took place whilst the survey was still available and the participants of the interview were able to see anonymised transcripts of their interview. There were specific questions focussing on awareness, accessibility and preparedness.

Response rates Survey completion results were as follows: $2017 \mathrm{Y} 1(25 / 143$ students), Y2(35/156), Y3 on campus (16/104), Y3 placement (6/13), Y4 (10/55); 2018 Y1 (28/136), Y2 (25/147), Y3 on campus (16/137), Y3 placement (3/14), Y4 (7/41). Only data with valid combinations of current course and previous course (survey questions 1/2) are included, which does include some repeating students.

Student responses to Likert based questions are highlighted in Figures 2-4. The number of free answer comments were as follows: Question 4 (53 comments in 2017; 48 in 2018); question 6 (24; 11); question $9(11 ; 8)$. Question 8 was given in 2017 only with 8 comments from year 2 students and 4 comments from year 3 students regarding the changes between model 1 and model 2 .

It should be noted that the year 3 cohort in 2017 is the same as the year 4 cohort in 2018, and so on, but not necessarily the same students who responded each year.

\section{Discussion}

The aim of this pilot was to gain an indication of whether the new H\&S processes had been favourable overall and identify any potential pockets of limitations in terms of preparedness and accessibility.

\section{General preparedness}

The general impression from figure 2 suggests that students mostly believe the H\&S training they received had helped prepare them for their current lab course, with only one occurrence of a year 4 student disagreeing. This initially suggests both model 1 and 2 are adequate. The free answer comments (survey question 4) mostly suggested that their preparedness was due to the H\&S lectures (all years), pre-lab tests (years 1-3) and research group specific training (years $3 / 4$ ) as the main reasons. Very few commented on the H\&S documentation or additional assignments until prompted by later questions in the survey. This was mostly confirmed in the interview where year 2 students could easily recall safety lectures they had had on NMR and explosions from six months earlier, but needed major prompting to realise $\mathrm{H} \& \mathrm{~S}$ training also requires a level of structured autonomous learning.

Concerns raised by students in years $1 / 2$ who answered 'Partly' to survey question 4 linked to very specific circumstances, such as waste disposal or general lab inductions; these are areas that have improved since this pilot. Other aspects of the free answer comments link to individual needs and confidence but there was a clear theme regarding thinking about H\&S again in a real-time context:

"The pre labs helped me to prepare so I knew the risks... and the demonstrators were able to help as well".

This was confirmed in the interview:

"a lecture on just waste would be more beneficial than explosions.... Waste is something that people do constantly"

Whilst the specific example of explosions is used, the general principle of pertinent $\mathrm{H} \& S$ 
A consideration of two models of health and safety training for undergraduate chemists

training is important and something to be considered during $\mathrm{H} \& \mathrm{~S}$ training.

Year 4 students from 2017 had not experienced model 2 whereas the 2018 cohort had during their year 3 . However, comments from both cohorts were reasonably consistent (survey questions 4/9), usually highlighting flaws in knowledge or processes for their specific projects, such as theoreticians being forced to attend safety lectures even though it 'wasn't needed', or gaps in their specialist knowledge, such as high-pressure systems, Schlenk-line use, etc. There were comments such as:

\section{"Basic training is exemplary, however, upon moving into a research lab, there were certain areas, ie fire extinguisher training, which are not covered beforehand."}

Other similar comments regarding glove use, eye-wash stations, exposure limits were discussed, and whilst we do offer such training, ensuring periodic reinforcement is key, linking to the idea of pertinent training.

\section{Preparedness: Model 1 vs model 2}

Comments from students who were either on industry placement at the time of data collection, or those who had completed an industrial placement in the previous year, gave insightful and consistent comments regarding preparing their own risk assessments. One comment from a 2018 student on placement (so completed model 1 during their first year only):

\footnotetext{
"I had to write my own CoSHH, risk assessment, and SSoW.

Whilst the questionnaires we had to complete last year gave a fuller background and I was more competent in the lab because of it, I still found myself referring to the knowledge I gained from writing the basic 1st year coshh systems during the course of this year [ed. whilst on industrial placement]."
}

Whilst the new system (model 2) does address these issues, it does so during year 3 when students are out in placement, so an understandable negative of model 2 is possibly not preparing industrial placement students appropriately. Since year in industry is often considered the key desirable graduate attribute, this is a potential limitation.

When comparing survey questions linked to preparedness (3/4/5c/7d/8, Figures $2-4)$, and using question 3 as a benchmark, it's clear that students in years 1-3 have mixed views when thinking about the new pre-laboratory requirements and were undecided on whether model 1 or model 2 was favourable. Interestingly, only two students who stated a neutral opinion or preference for the old system (model 1) offered clarification stating:

"This is a bit of an awkward one because having to do your own $\mathrm{COSHH}$ forms did sometimes take up too much of your time however it actually meant I understood the hazards of the chemicals I was using. It was nice to have the COSHH forms already completed in third year but I did find it meant that I wasn't as careful with chemicals as I should have been."

There were, however, 11 comments praising model 2 generally:

$$
\begin{gathered}
\text { "Being quizzed on the COSHH is } \\
\text { far more effective than having us } \\
\text { just simply copy it out." }
\end{gathered}
$$

\section{Accessibility}

There was a concern that creating the $100 \%$ barrier would be challenging for some students. However, looking at year 1 attempts data in 2017, the average number of attempts to reach $100 \%$ was $2.5,3.7$ and 1.6 for the three year 1 lab courses, but there were some who took significantly more attempts. There were a few occasions where some pre-lab questions were vague or had the wrong answer to an MCQ question selected, which caused some frustrations, but occurrences of these have diminished over time.

Students believed the $100 \%$ requirement was fair (survey question 5a), with over two-thirds of respondents strongly agreeing, and only two 
disagreeing. One who disagreed still made the case about wanting to be challenged, but simply didn't like any questions that were recall based:

"I believe with safety it should be more about understanding the real risks... A sensible question will not just test the question asked it will make students read the full procedure first"

The year 2 students in the interview were quite clear on their preferences also, preferring model 2 but stating model 1 was easier. Numerous comments from the survey indicate indirectly that the online test process was a harder barrier to overcome, but indicated it was more active learning than passively copying out $\mathrm{COSHH}$, typified by the following year 2 student in 2017:

\footnotetext{
"Writing own COSHH in first year was a learning experience, for second year however, it would have just been tedious. Pre-labs took longer to complete this year, but overall less time was required in preparation for labs as no $\mathrm{COSHH}$ was needed to be written out, so overall, quicker. It is more important for knowledge of the COSHH to be tested than simply copying it out"
}

\section{Conclusion and future work}

A curriculum re-development around H\&S training for undergraduate chemistry students was introduced with students' general awareness of H\&S training probed. Model 1 (old model) focussed on student generated $\mathrm{COSHH}$ development with variable approaches to checking understanding. Model 2 (new model) focussed on student understanding of instructor prepared $\mathrm{H} \& S$ documentation via a minimum requirement of $100 \%$ in pre-laboratory safety tests. Without prompting, it was clear student still consider the traditional lecture as the main source of H\&S training. With prompting as both the questionnaire and interview progressed, the view did change. Of the two models used, it's clear that both have their benefits and limitations in terms of preparing different students at different stages of their programme, and ideally a combination of both models could be implemented. However, we deliberately moved away from student generated $\mathrm{COSHH}$ due to concerns with consistency, collusion and deep engagement and wanted to focus on more active forms of $\mathrm{H} \& \mathrm{~S}$ training. Student responses suggest the requirement of obtaining $100 \%$ pass mark for online safety tests fair and very few thought the switch from model 1 to model 2 was unfavourable. However, it is clear that more opportunities for students to generate their own risk assessments need to be considered.

The whole process of model 2 was approved by the University Safety Advisory Office and considered best practice within the University with the Chemistry team winning the University staff award for Health, Safety and Wellbeing in 2018.

\section{Acknowledgements}

The author would like to thank the numerous colleagues who put time and effort into the development of the new system outlined by model 2 as this curriculum change was truly a departmental effort.

The author would like to acknowledge the University for the award of a Learning and Teaching Fellowship (2017) which formed the basis of this pilot evaluation.

\section{References}

ACS, ACS Guidelines and Evaluation Procedures for Bachelor's Degree Programs, Available at: https://www.acs.org/content/dam/acsorg/abou t/governance/committees/training/2015-acsguidelines-for-bachelors-degree-programs.pdf (accessed 10th August, 2019)

Agustian, H.Y. and Seery, M.K. (2017) Reasserting the role of pre-laboratory activities in chemistry education: a proposed framework for their design. Chemistry Education Research and Practice, 18(4), 518-532. DOI: 10.1039/C7RP00140A.

Alaimo, P.J., Langenhan, J.M., Tanner, M.J. and Ferrenberg, S.M. (2010) Safety Teams: An Approach To Engage Students in Laboratory 
A consideration of two models of health and safety training for undergraduate chemists

Safety. Journal of Chemical Education, 87(8), 856-861. DOI: 10.1021/ed100207d.

Artdej, R. (2012) Investigating undergraduate students' scientific understanding of laboratory safety. Procedia-Social and Behavioral Sciences, 46, 5058-5062. DOI: 10.1016/i.sbspro.2012.06.385.

Benderly, B., The Landmark Patrick Harran Case Ends Inconclusively, Available at: https://www.sciencemag.org/careers/2014/07// andmark-patrick-harran-case-endsinconclusively (accessed 10th August, 2019)

Blackburn, R.A.R., Villa-Marcos, B. and Williams, D.P. (2019) Preparing Students for Practical Sessions Using Laboratory Simulation Software. Journal of Chemical Education, 96(1), 153-158. DOl: 10.1021/acs.jchemed.8b00549.

Clemons, T.D., Fouché, L., Rummey, C., Lopez, R.E. and Spagnoli, D. (2019) Introducing the First Year Laboratory to Undergraduate Chemistry Students with an Interactive $360^{\circ}$ Experience. Journal of Chemical Education, 96(7), 1491-1496. DOI: 10.1021/acs.jchemed.8b00861.

Confederation of British Industry, The Right Combination: CBI/Pearson Education and Skills Survey 2016, Available at: http://www.makingthemostofmasters.ac.uk/me dia/microsites/mmm/documents/cbieducation-and-skills-survey-2016.pdf (accessed 10th August, 2019)

Cranwell, P.B., Davis, F.J., Elliott, J.M., McKendrick, J.E., Page, E.M. and Spillman, M.J. (2017) Encouraging independent thought and learning in first year practical classes. New Directions in the Teaching of Physical Sciences, 12(1).

Han, D.-H. and Park, M.S. (2018) Survey of awareness about hazardous chemicals of residents living near chemical plants in South Korea. Ind Health, 56(4), 285-291. DOI: 10.2486/indhealth.2017-0119.

Hanson, S. and Overton, T., Skills required by new chemistry graduates and their development in degree programmes, Higher
Education Academy, Physical Sciences Centre, 2010.

Hill, R.H. (2016) Undergraduates Need a Safety Education! Journal of Chemical Education, 93(9), 1495-1498. DOI: 10.1021/acs.jchemed.5b00825.

Huston, E.M., Milligan, J.A., Powell, J.R., Smith, A.M., Neal, D., Duval, K.M., DiNardo, M.A., Stoddard, C., Bell, P.A., Berning, A.W., Wipf, P. and Bandik, G.C. (2018) Development of an Undergraduate Course in Chemical Laboratory Safety through an Academic/Industrial Collaboration. Journal of Chemical Education, 95(4), 577-583. DOI: 10.1021/acs.jchemed.7b00599.

Karapantsios, T.D., Boutskou, E.I., Touliopoulou, E. and Mavros, P. (2008) Evaluation of chemical laboratory safety based on student comprehension of chemicals labelling. Education for Chemical Engineers, 3. DOI: 10.1016/j.ece.2008.02.001.

Kemsley, J. (2009) Learning from UCLA. Chemical \& Engineering News, 87(31), 29-31.

Kemsley, J. (2016) How educators are teaching students to assess risk in the lab. Chemical \& Engineering News, 94(16), 26-27.

Kirton, S.B., Al-Ahmad, A. and Fergus, S. (2014) Using Structured Chemistry Examinations (SChemEs) As an Assessment Method To Improve Undergraduate Students' Generic, Practical, and Laboratory-Based Skills. Journal of Chemical Education, 91(5), 648-654. DOI: 10.1021/ed300491c.

Kumasaki, M., Shoji, T., Wu, T.-C., Soontarapa, K., Arai, M., Mizutani, T., Okada, K., Shimizu, Y. and Sugano, Y. (2018) Presenting Safety Topics Using a Graphic Novel, Manga, To Effectively Teach Chemical Safety to Students in Japan, Taiwan, and Thailand. Journal of Chemical Education, 95(4), 584-592. DOI: 10.1021/acs.jchemed.7b00451.

Lucas, T. and Rowley, N.M. (2011) Enquirybased learning: experiences of first year chemistry students learning spectroscopy. Chemistry Education Research and Practice, 12(4), 478-486. DOI: 10.1039/CORP90016H. 
A consideration of two models of health and safety training for undergraduate chemists

QAA, Subject benchmark statements: Chemistry, Available at: http://www.qaa.ac.uk/docs/qaa/subjectbenchmark-statements/sbs-chemistry14.pdf?sfvrsn=99e1f781 14 (accessed 3rd February, 2019)

Royal Society of Chemistry, RSC Accreditation of Degree Programmes, Available at: http://www.rsc.org/Education/courses-andcareers/accredited-courses/bscaccreditation.asp (accessed 3rd February, 2019)

Royal Society of Chemistry, Learn Chemistry Health and Safety tutorials, Available at: http://www.rsc.org/learnchemistry/collections/health-and-safety/ (accessed 10th August, 2019)

Staehle, I.O., Chung, T.S., Stopin, A., Vadehra, G.S., Hsieh, S.I., Gibson, J.H. and GarciaGaribay, M.A. (2016) An Approach To Enhance the Safety Culture of an Academic Chemistry Research Laboratory by Addressing
Behavioral Factors. Journal of Chemical Education, 93(2), 217-222. DOl: 10.1021/acs.jchemed.5b00299.

Stuart, R.B. and McEwen, L.R. (2016) The Safety "Use Case": Co-Developing Chemical Information Management and Laboratory Safety Skills. Journal of Chemical Education, 93(3), 516-526. DOI: 10.1021/acs.jchemed.5b00511.

The National Archives, Health and Safety at Work etc. Act 1974, Available at: http://www.legislation.gov.uk/ukpga/1974/37 (accessed 10th August, 2019)

Veiga, N., Luzardo, F., Irving, K., RodríguezAyán, M.N. and Torres, J. (2019) Online prelaboratory tools for first-year undergraduate chemistry course in Uruguay: student preferences and implications on student performance. Chemistry Education Research and Practice, 20(1), 229-245. DOI: 10.1039/C8RP00204E. 